\title{
Adapting and Evolving-Learning Place Cooperation in Change: A Comparative Study of the Vocational and Educational Training System in China and Germany
}

\author{
Xing Liu and Lutz Leonard Schuppener
}

\begin{abstract}
China's and Germany's economies hold very strong positions in a global context. Why is that so? One important factor of a well-functioning economy is a county's educational and vocational system, which in the future will have to meet particular challenges. Germany's dual system of combining practical and theoretical education is widely acknowledged as an example of achieving good results. With China's Policy of Reform and Openness (1978) the process of international exchange and cooperation in vocational training started to develop. 40 years of international exchange and cooperation produced new forms of learning: The School-Enterprise Cooperation. On this basis, models of learning place cooperation will be discussed and in this paper. Moreover, it will also be discussed how the two systems could benefit from each other. For the comparative study Bereday's four stage method will be applied.
\end{abstract}

Index Terms-VET, China, Germany, school-enterprise cooperation, education.

\section{INTRODUCTION}

\section{A. Theoretical Background and Aim of the Paper}

Germany's economic success after the Second World War resulted - among other things - from the German vocational education and training (VET) system. This is characterized by its dual system, teaching students at school for the theoretical and at the workplace for the practical part. This way of learning is commonly acknowledged by employers, employees and politics alike and has gained an international reputation.

China, on the other hand, is currently in the process of changing from an emerging to a developed country. Therefore the demand for a highly qualified workforce is rising. In the Chinese society, there is a tradition of great respect for an academic education. Meanwhile however, a significant number of graduates find themselves in jobs which are below their qualification. At the same time, the number of qualified graduates does not suffice the actual demand in the working world. Therefore, it is necessary to improve and specify vocational training which makes employees fit for the permanently changing demands of the working world. Up to now, however, vocational training is

Manuscript received January 9, 2019; revised June 11, 2019

$\mathrm{X}$. Liu is with the Institute for Vocational and Business Education, Didactics of Economics, Leuphana University Lueneburg, Germany (e-mail: xing.liu@leuphana.de).

L. L. Schuppener is with the Institute for Management and Organisation, Leuphana University Lueneburg, Germany (e-mail: lutz.schuppener@stud.leuphana.de). not attractive or appreciated.

So China is looking to Germany as an example and is trying to adapt to its dual system. This already happened as early as 1988 when China copied the system with all its elements (equipment, apprenticeship, teaching materials etc.). This did not produce the effect that was intended. So, in the following years, this system was tested and modified to fit China's conditions and after 40 years of cooperation and exchange a new form of learning place cooperation has been established successfully.

According to Charles Ragin "It is not possible to think without comparing things" [1], in other words: "thinking means comparing". Learning place cooperation as an 'adjustment tool' in order to improve the qualification of the workforce can be more adequately evaluated when seen in the context of a different educational system. Only then does the potential of innovation become evident. Subsequently, this paper will discuss and compare the current models of learning place cooperation in both countries, China and Germany and will then point out the differences.

There already are quite a number of international comparative research studies on vocational training. This paper will refer to relevant studies dealing with this subject. For the comparative study concerning the learning place cooperation Bereday's four stage method (1964) will be applied [2]. Publicly available documents and sources have been integrated in the analysis of the contents.

According to Hörner [3], Georg [4], Frommberger and Deißinger [5] comparing education and vocational training internationally can be done on the basis of three aspects of interest: the ideographic aspect (looking at a specific characteristic), the melioristic aspect (looking for improvement) and the evolutionary aspect (looking at the potential for development and general differences).

The present paper is a study based on the ideographic and melioristic aspects, whose results cannot only be applied to the German or Chinese situation in vocational training, it is also trying to stimulate changes in the vocational training of both countries and thus point to a sustainable future in this field. Therefore, we will focus on two main questions: What do the two countries have in common and how do they differ concerning learning place cooperation? How far can they be compared and how can they profit from each other?

\section{B. Method and Structure of the Paper}

The four steps of comparison method by George $\mathrm{Z}$. Bereday (1920-1983) has long been established and tested as a basis for international comparisons of educational standards [6]. This model is divided into the phases of 
description, interpretation, juxtaposition and comparison. In the first phase of description existing data (empirical and literary) which seem promising in the given context are systematically listed. In the second phase of juxtaposition these data will be analyzed and evaluated. This will happen with regard to various other disciplines. The third phase of juxtaposition will systematically contrast the specific findings characteristic of each country gained in the first two phases. Parallels and differences will thus become evident. The last phase will compare the findings directly and simultaneously. Theses that have been established in the third phase will either be verified or falsified. Following this phase, normally conclusions can be drawn.

Following the method and the objective of this paper, it will have the following structure:

The following chapters will define the term of "learning place cooperation" and how it can be applied to the context of this paper. An exemplary description and interpretation of the objects of research according to the model by Bereday will then follow and form the basis for comparing learning place cooperation in vocational training. This will also be the basis for the next steps of juxtaposition and comparison. Concluding, the above-mentioned research questions will be reflected.

\section{LEARNING PLACE COOPERATION OF VET IN COMPARISON}

The development of learning place cooperations and its significance in the VET system depend on the VET tradition and the culture of cooperation of the respective country [7]. The following chapter deals with the learning place cooperation of VET in China and Germany. In order to ensure a basis of understanding for the terminology, the theoretical context of the learning place cooperation will be explained before the practical forms of cooperation in China and Germany are presented.

\section{A. Learning Place Cooperation - A Conceptual Clarification}

"A place of learning is a recognized public education institution that organizes learning programs. The term 'place' first of all means that learning is not only temporally (...) but also locally structured. However, it is not just defined by space but also in its pedagogical function" [8]. Learning places are therefore to be understood institutionally [9], [10], which may be both public and private institutions. In Germany, the places of learning are listed in the Vocational Training Act amended in 2005. Places of learning or learning areas include business enterprises and comparable institutions outside the economy (occupational training), vocational schools (school vocational training), other vocational training institutions outside of school and occupational training (external vocational training) [11].

Cooperations must first and foremost always be regarded as a means to an end [7]. Therefore, the term cooperation generally describes the cooperation and interaction of different actors on the basis of common interests [12]. Among other things, a distinction should be made between coordination and cooperation. Cooperation is understood as the cooperation of several members for a limited period in fulfillment of a task. In contrast, the term "coordination" means working together in the sense of permanently shared tasks. Against this background, the tasks and problems of a "learning place cooperation" would be "coordination tasks" to be precise. However, in popular language, the term "learning place cooperation" is still commonly used [10].

According to the German Vocational Training Act, an interaction of the learning venues (occupational, school and extracurricular VET) in the implementation of VET is to be established [11]. Collaborative learning is therefore understood as the technical-organizational and pedagogical interaction of teaching and training staff at the abovementioned learning venues, which takes place at the local, regional, national or international level. The aim of this cooperation is to achieve a closer coordination between company and school training centers and to better interlock theory and practice in vocational education and training [9]. The following comparison focuses especially on the learning cooperation in the context of the initial vocational training of both countries.

\section{B. Description and Interpretation}

After introducing the topic of learning place cooperation and clarifying the terminology, the forms of learning place cooperations in China and Germany will be presented below. For this purpose, the work makes use of the four-phase model of Bereday: The specific characteristics of both countries are first described objectively and separately from each other (description). After this the second phase (interpretation) will also be applied in this chapter.

\section{1) The traditional learning relationship in China}

The idea of combining learning and gainful employment has a long tradition in China. In the traditional learning relationship, the technical abilities and skills within the family or experienced workers were passed on to the apprentice. In the Sui dynasty (581-618 AD) and Tang Dynasty (618-907 AD), the imperial government for the first-time established craft enterprises in which skilled workers were trained in apprenticeship. It can therefore be stated that the learning relationship must be regarded as a period of gaining maturity [13]. This training model has four characteristics: teaching by word and example, mental teaching / learning, on-site teaching, master-apprentice relationship [14]. In craft workshops, mostly in a master family, master and apprentice work together. The apprentice acquires knowledge or skills under the guidance of experienced workers known as "masters". The Chinese term "master" cannot be compared with the German "Meister". "Master" in China is a respectful form of address for experienced workers who share their experience, knowledge, skills and abilities with others. There is no systematic educational structure in this area. For this reason, the supply of curricular training is very broad. In this kind of employment, the apprentices also suffered oppression and exploitation, because they had to work without pay as a helper for the masters. A trained apprentice had to work for the same master in the future and was not allowed to "go outside" in order not to betray the "secret recipes" to other workshops. In past centuries, traditional learning relationships were the essential form of skilled worker 
education in China [15].

After the establishment of the People's Republic of China in 1949 , there was a comprehensive transformation in the traditional learning relationship aiming to end exploitation, to guarantee the basic rights of the apprentice and to train the skilled workers in the planned economy. After 1958, there were repeated attempts to establish a new training model with the so-called "half-work / half-school" system. In this respect, the further development of the traditional learning relationship is referred to as a modern learning relationship characterized by the "cooperation" of different learning locations in vocational education, colloquially "school-enterprise cooperation" [15].

\section{2) The school-enterprise cooperation in China}

The idea of the School-Enterprise Cooperation has a long history. The philosopher Confucius created the first basic ideas for linking "learning and gainful employment". After the founding phase (e.g. the cultural renewal movement of May 4, 1919) and the trial phase (e.g. the founding of the skilled workers' schools, partly also the vocational schools in the 1950s), there has been a great change in vocational education in China since the 1980s. The educational system at the end of the 1980s was a network of "general and vocational schools whose diversity is the expression of far-reaching differentiation processes since the end of the Cultural Revolution in 1976" [16]. With the start of this "reform and openness policy" (1978), Deng Xiaoping initiated a large scale of international exchanges and cooperations, which led to new challenges for the education and training system. Several western countries had already been operating successfully on the global education market for decades. Examples include the "Dual System" in Germany, the National Vocational Qualifications (NVQs) in the United States and the UK, and the Technical and Further Education (TAFE) in Australia and the United States. As a result, a defining feature of the current Chinese vocational training system is the integration of foreign elements.

The Chinese School-Enterprise Cooperation is still at a relatively early stage of development. Based on the Chinese educational tradition, the current structure of the "Enterprise Cooperation Program" integrates various proven foreign elements and can be summarized under three aspects:

The first aspect of the program concerns the administrative or stimulating actions of governments or sector organizations at all levels. Although they have assured that companies are obliged to support the program, they have not yet specified how this is to be implemented. In addition, no cooperation mechanisms have yet been developed that define the cooperation between schools and companies. [17]

The second aspect involves cooperations between vocational schools and companies. China has developed eight different models for this purpose, which differ in the combination of time, space and organizational factors. However, the implementation of the measures should be treated with caution, as the terms are vague and the legal consequences of violations have not been specified. These learning cooperations between vocational schools and companies primarily involve specialized vocational schools. There are also different types of cooperations in terms of the factors - duration, purpose and extent of cooperation. These characteristics are summarized below. [17]

- Deviding school years model

This model includes two variants. In the first version, the " $2+1$ " model, the trainees spend the first and second years in school and do a job-related internship in the third year. This is currently the most widely used model in China. The second less common version is the "remote places" model. In this model, the apprentice spends the first school year in his rural home region. The second year is spent in a school in the city, the third year is used for a work-related internship, adapted to the local conditions. [17]

- Half-work-half-study model

Within the "half-work-half-school" model, schools and companies jointly develop training content for a specific period of time or for a semester. This has the advantage that a combination of theoretical and practice-relevant content is achieved. Furthermore, students from poor families can successfully complete their education [17].

- Flexible arrangement model

This training is also known as "non-school vocational training". Within the flexible arrangement model, learning processes are attuned according to seasonal and periodic conditions, which are therefore very helpful for the companies associated with them, since varying personnel requirements can be compensated for in the respective periods [17]. This training takes place in three stages: lower, intermediate and higher training, with each lasting 3 to 6 months. The content of the training as well as the number of apprentices always depend on the current needs of the companies [18].

- Training orders model

International companies, such as Siemens select a certain number of graduates to train them specifically for the needs of the company. In return, the company pays a corresponding amount to the vocational school. The advantage of the model of "training assignments", which are accompanied by joint curricula, lies with the companies, because they can "order" graduates in advance as needed [17].

- Work-study bases within the enterprises model

The fifth model is a further development of the training orders model, in which the companies ensure both educational and practical training with their own instructors. This program is very popular with high-tech companies and is an advantage for schools as they cannot provide such highly technical training otherwise. This has the advantage that companies set up separate training workshops for students, which in turn means that resources are saved by the school [17].

- Sector-led model

Within the sector-led model, small and medium-sized enterprises seeking to collaborate on learning places are brought together, and independent platforms are set up to organize cooperation and offer internships. A current example of this cooperation is the Henan Supply and Marketing Cooperation. Under this name, more than 1000 medium and small companies have joined forces and arranged a training cooperation with five vocational schools. The companies offer internships and internal training and provide part-time teachers with subject-related courses. In 
this respect, these small and medium-sized enterprises profit from the cooperation of learning places [17].

- Teaching factories model

In this program, companies transfer their production facilities to schools. This results in a symbiosis between school and business. The company provides machines and skilled workers for training and in return the schools produce apprentices for the company. As a result, students are given practical training and are therefore of high value to the company later on. It also has benefits for the school as they can closely control and monitor the learning process. This is not only convenient for the students, but also helps the school to gain more control over their education [17].

- Enterprises program replacement model

Companies provide schools with curricula developed in-house. When a school decides to enter into this type of cooperation with a company, it receives the technical equipment, trained personnel and financial support. The benefits for the company are equally complex: the company not only has control over the training content, it can also better market its products. Therefore, this type of cooperation is very popular e.g. with car manufacturers such as GM and Toyota [17].

The third aspect of the "School-Enterprise Cooperation" is the so-called vocational education group. This model can be traced back to the early 1990s. The aim is to create a platform for schools and companies to enable the cooperative training of workers. It allows educational resources to be integrated so that companies of different levels can network with each other and share hardware resources. Companies in this group are therefore connected to the schools. This means that schools as well as companies offer training basics. Companies also participate in the development of courses and teaching materials. Joint project developments are also required in this way, internships and employment opportunities for school students are offered. The "vocational education group" as a network is based on the voluntary participation of various elite schools and companies. The system connects local schools with local businesses or local resources to maximize benefits for all those involved. [17]

\section{3) The dual vocational training in Germany}

The dual vocational training system, which has proven its worth in Germany for decades as a qualification machine for German vocational training, enjoys a very good reputation abroad. In 2017, there were 327 different training occupations in Germany, i.a. in the commercial, technical, craft, social or medical field, whereby the training supply is regulated by the market [19]. The present system of dual vocational training is not the result of purposeful planning and development, but a consequence of a complex historical development. In Germany vocational training is not only a matter for the school, but a systematic "project" for which society as a whole bears responsibility in terms of planning, implementation and further development. In a market economy environment, various actors (federal, state, business / employers, trade unions and political parties) engage in the development of vocational education and training at all levels.
The concept of the dual system is merely a generic term for the non-uniform organizational structures created by the multitude of different learning situations and places of learning. As Fig. 1 shows, the duality in this context stands for the parallel training in vocational school and company, whereby the company provides the practical training and the vocational school general education as well as the theoretical vocational training [20].

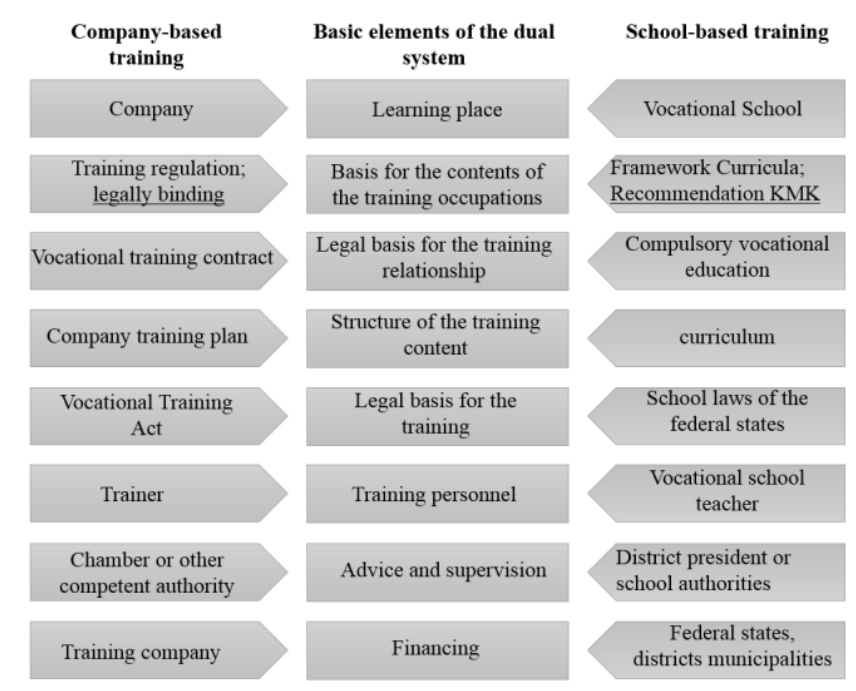

Fig. 1. Duality of vocational training (own illustration, cf. [20]).

In the traditional model of dual training, trainees are trained three to four days a week at their company. This initial training, which is accompanied by a full or part-time instructor, is standardized by the Vocational Training Act and carried out as part of a training contract based on a training regulation. Trainees have the right to choose their training company freely. However, companies can choose their apprentices freely, whereby the principle of freedom of contract applies. The state, on the other hand, determines the framework conditions for the operational part of the training in order to ensure the interoperability of the acquired qualifications. The company training is supervised by the responsible body (chamber). The financing is provided by the training company. The trainee receives a specific remuneration for his apprenticeship (see Fig. 1).

The apprentices attend vocational school one to two days a week. There is also the possibility of the block model in which the theoretical training takes places as full-time blocks lasting several weeks a year and for the remaining time the trainees are exclusively in company-based training. Occupational learning at the vocational school is determined by the school laws of the federal states. Classes are taught by teaching staff with a university degree and work experience in at least one company. The content is determined by the framework curricula of the Conference of the Ministers of Education specific to each profession. The school funding is provided by the public-school board [20] (see Fig. 1).

In addition, a training contract between the trainee and the training company is required. According to the Vocational Training Act, the training period should not be less than two years and not more than three years. There are exceptions in technical occupations, which usually take a longer training period, in contrast to the "less demanding occupations". 
The breakdown of the content into vocational as well as general education is to enable the trainees to fulfill their tasks in their profession as well as to contribute to the shaping of society and the working world concerning their ecological and social responsibility. In order to achieve a stronger integration of practice and theory in vocational education, the lessons have been structured from 1996 onwards by specific learning field framework curricula. This learning field concept calls for action-oriented teaching and makes use of vocational problems as a point of reference. The competence to be acquired at the end of a learning process links individual competence, expertise and social competences [21]. A final examination is used to determine whether the trainee has acquired the required vocational competence [11].

The unique combination of theory and practice, of school and enterprise outlines the German vocational training and distinguishes it from all other European countries. "This justifies its efficiency in the vocational integration of young people and its international impact" [22]. Nonetheless, the dual training of Germany also has some structural problems, for which solutions are sought intensively in order to guarantee the future viability of the dual system and ensure its high-quality.

\section{4) Cooperations through collaborative training in Germany}

The second form of training in learning cooperation is the collaborative training which was included in the law in 2005 as follows: "To fulfill the contractual obligations of the trainers, several natural or legal persons can cooperate in a training network, as far as the responsibility for the individual training sections as well as for the training time is ensured in total (collaborative training)" [11]. For some technical occupations (e.g. car mechanics), a company cannot provide all the training content of the training framework plan. That is why several companies train the young person together, i.e. individual training sessions are taught in other companies. The literature frequently refers to four classical organizational forms of collaborative training (see Fig. 2):

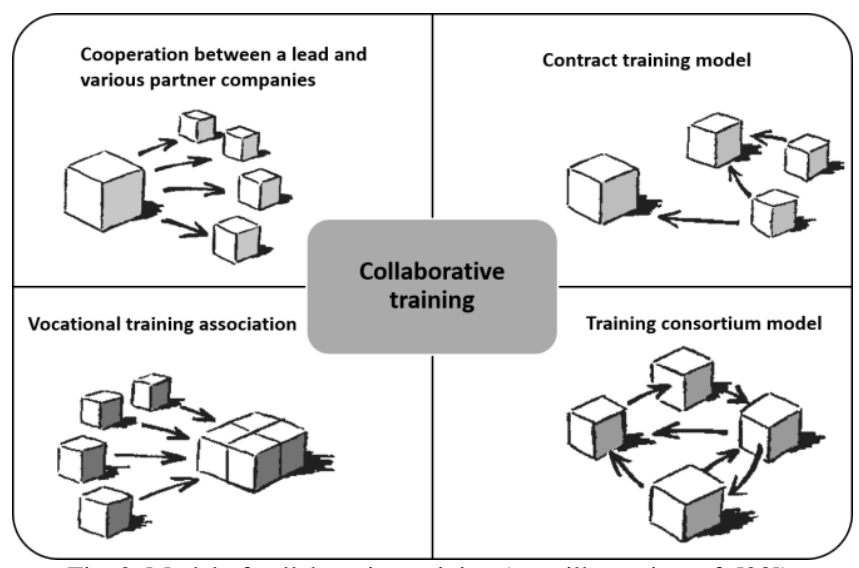

Fig. 2. Model of collaborative training (own illustration, cf. [23]).

The first variant of the collaborative training is a cooperation of a lead company and various partner companies. A vocational training contract is concluded between the trainee and the lead company. The lead company as the originating company organizes and coordinates the planning and sending of the apprentices to partner companies, which take over some training sections. These partner companies benefit from the experience of the lead company [23].

In the contract training model, companies with free training capacity cooperate with the companies that use this capacity. Thus, the training company is compensated for the training as a service "sold" on the market. Because this form of training is flexible, it is the most widely used form of collaborative education [23].

In the case of the vocational training association model, the latter acts as a trainer in order to take on the training tasks of the member companies, thus minimizing the administrative burden on individual companies [23].

Another variant is the training consortium model. Here training contracts are concluded with the training companies involved, which in turn provide training to a training center or another company. Each operation is thus both a receiving and donating company. The advantage for this loose grouping of companies is, that collectively they can offer a broader range of topics [23].

The collaborative training remains an interesting instrument with advantages for companies and trainees. In this form of training, the range of training places and the quality of training are increased or secured [24].

\section{Results: Juxtaposition and Comparison}

The third phase of Bereday's model, called Juxtaposition, takes up the findings and summarizes characteristics of the learning place cooperation of both countries. This juxtaposition makes it possible to identify similarities and differences in Germany and China that will be presented in the following three aspects (comparison).

At first glance, the Chinese learning cooperation is very similar to the German system. Both China and Germany have a long tradition of learning place cooperation in a professional context. In both countries, vocational training has become more important over the years, with learning venue cooperation practiced as an important tool for improving the quality of VET. This leads us to the question which similarities in the development and structure of the systems are recognizable and whether the systemic developments of the respective country also make it possible to draw conclusions concerning future developments.

One challenge that arises from the size of China is that learning collaboration requires a variety of measures. In order to adapt the vocational training to the current requirements, more than eight different models are being tested in practice in China. This does not in this form occur in Germany. Whether this is a general advantage or a disadvantage for the quality of the training cannot be assessed here. However, concerning the comparison of models the following should be considered:

- In Germany great value is placed on practical training. The dual system is special due to its ratio of theory and practice of 3:7. However, one also recognizes in Germany that despite the close relationship of theory and practice, comparable problems exist, such as for 
example a shortage of skilled workers, which are to be tackled from different perspectives. Vocational training efforts are currently focusing on three different directions. First of all, the learning place cooperation is understood as a way of generally shortening the training time. For this purpose, a better coordination of the training content should be made in order to avoid overlapping of the learning content. In addition, learning co-operation envisages a deregulation of the dual system with greater decision-making powers for the regional networks, in order to increase local responsibility and coordination. The reason for this demand is the rapid change in the requirements of the economy, the state and society. As a result, training regulations and framework curricula are getting outdated very fast. The third guiding principle deals with the current lack of training posts [10]. China has already implemented the first guiding idea and shortened its training. This orientation can also be compared with the model of the "flexible arrangement". The criticism of this Chinese version lies in the fact that in this way only practical training takes place and cooperation with the schools is no longer practiced, consequently this type of training is limited to the requirements of companies. The second central idea, which is discussed in Germany, involves the deregulation of the dual system, which also appears in various models of the Chinese School-Enterprise cooperation. One example is the sector-led program, which brings together small and medium-sized enterprises seeking to collaborate on learning places. The "sector-led" program reveals many parallels to the German system. In Germany, the Chambers of Commerce, Industry and Trade take over agreements with the various state ministries of education in order to develop the curriculum priorities for the respective training occupation, thus adapting the schools' curricula to current needs and challenges.

- For Germany it has to be stated that the promotion and securing of the training success of special target groups plays an important role, whereby integration and inclusion are more in the focus than in China. This is illustrated by the "deviding school years model" in which apprentices from different places of origin either go through the " $2+1$ " model or the "remote places" model.

- The Chinese program "Training assignments" is difficult to find in the German training system, but some form of it is also being exercised in Germany, particularly by international companies that offer a dual degree program with training at a central location.

It is obvious that China has developed two separate programs: "Learning / Teaching Factories" and the "Enterprise Program Exchange". In both cases, companies are heavily involved in the training system and create the curricular requirements according to their own needs. In addition, the trainees are an active part of the production chain. These two measures represent a completely new kind of learning place cooperation, which does not exist in a comparable form in Germany. It can also be seen that companies in China can exert enormous influence on the training content within the presented models. In this context, there is a risk that companies can change training in their favor.

- China has developed yet another aspect of its reform: the "Vocational Training Group", comparable to the networking of learning place cooperation in Germany, with the aim of building a network between the "learning places". The difference between the learning venues in both countries is that in China the "Vocational Training Group" is a platform for schools and companies to enable cooperative training of workers, while in Germany the collaborative training education takes place by means of connecting several companies.

\section{DiSCUSSION AND SIGNIFICANCE}

A comparison of the learning place cooperation of Germany and China represents an enormous challenge and shows mixed results: A learning place cooperation, as it is systematically practiced nationwide in Germany, in China only exists in individual schools and companies. Why is that so? Reasons can be seen in the different status of science and society, a different acceptance of VET as well as an established or dynamic learning place cooperation.

The Chinese School-Enterprise Cooperation, which integrates various high-quality foreign elements based on the Chinese educational tradition, is still in a relatively early stage of development. Especially in today's China, the change is clearly noticeable. The "School-Enterprise Cooperation" program has already achieved first successes after a short time. Although the experimental implementation of the foreign elements in the Chinese education system at this point shows the importance of the interlocking between theory and practice for the quality of education, the theory-practice link in China's vocational training system is nevertheless increasingly criticized. Due to the size of China, the high number of students, the small size of the mechanical equipment and the widely differing qualification levels of teachers, it is difficult to carry out the implementation of the cooperation in China uniformly.

In Germany, on the other hand, there is a strong formal framework as the basis for cooperation in the form of the Vocational Training Act, or the crafts code in the craft trades sector, as well as state school laws. It should be noted that Germany, based on the learning field concept, pursues the learning location cooperation with the aim of providing trainees with comprehensive competencies and ensuring a stronger integration of theory and practice. This is reflected above all in the areas of action described above. Although the Chinese Vocational Training Act came into force in 1996, the cooperation on learning sites has so far not been legally binding due to the lack of guidelines of the various actors, due to legal provisions that have not yet been passed.

Both countries have in common that a well-functioning learning place cooperation is the overall goal of all participants. In China, however, two ministries (MoE and MoHRSS) are responsible for VET, which often have a different VET policy. In practice, this leads to overlaps and duplications in responsibilities, which might make it difficult to achieve an efficient, uniform and coordinated overall 
system and thus stand in the way of quality assurance. In contrast, in Germany there is a special institution for doing research on and further developing vocational education and training: The Federal Institute for Vocational Education and Training. It might be desirable to set up a "comparable institution" in China, which could be primarily devoted to vocational training.

The German model of learning co-operation is firmly anchored as a role model worldwide, but also comparatively static. In China, however, there is a wide variety of cooperation models, which are largely based on foreign models through international exchanges and cooperation (for example, Dual System, NVQs, TAFE, etc.). At the same time, China is promoting various educational projects abroad, e.g. Aid projects in Africa. That is why China acts both as a "recipient country" and a "donor country" in this area. Compared to China, Germany has always acted as a "donor country", endeavoring to export its "dual system" in the original without foreign elements. Especially in the wake of new challenges in the world of work, changing job profiles and new technology-related means of cooperation, Germany could probably also benefit from a stronger exchange with foreign countries. This question leaves room for further research.

Overall, it is clear that the learning place cooperations of both countries each have recognizable advantages and disadvantages. Given the tremendous speed with which China is generally developing, it becomes clear that both sides could learn more from each other in the future in terms of modern vocational education and training.

\section{CONFLICT OF INTEREST}

The authors declare no conflict of interest.

\section{AUTHOR CONTRIBUTIONS}

$\mathrm{XL}$ conceived of the presented idea, developed the theory and conducted the analysis; LS contributed to the conception of the research and to the writing, review and editing of the manuscript; all authors have approved the final version.

\section{REFERENCES}

[1] C. Ragin, The Comparative Method. Moving Beyond Qualitative and Quantitative Methods, Berkeley: University of California Press, 1987, P.1.

[2] G. Z. Bereday, Comparative Method in Education, Holt, Rinehart and Winston, 1964

[3] W. Hörner, "Technische modernisierung. Reformen im bildungswesen in vergleichender sicht,"Vergleichende Erziehungswissenschaft, vol. 19, no. 20, 1988, pp. 53-65.

[4] W. Georg, "Vergleichende berufsbildungsforschung,"Handbuch Berufsbildungsforschung, Bielefeld: Bertelsmann, 2006, pp. 186-193.

[5] D. Frommberger and T. Deißinger, "Berufsbildung im internationalen Vergleich -Typen nationaler Berufsbildungssysteme," Handbuch Berufs- und Wirtschaftspädagogik, Bad Heilbrunn: Klinkhardt, 2010, pp. 343-348.

[6] M. P. Amaral, "Methodologie und methode in der international vergleichenden erziehungswissenschaft,'Internationale und vergleichende Erziehungswissenschaft. Geschichte, Theorie, Methode und Forschungsfelder, Münster: Waxmann, 2015, pp. 107-130.

[7] D. Euler, "Über die entwicklungsbedingungen einer kooperationskultur,"Handbuch der Lernortkooperation (Bd. 1: Theoretische Fundierung, Bielefeld: Bertelsmann (Forum Wirtschaftspädagogik), 2004, pp. 305-318.
[8] D. Bildungsrat, Die Bedeutung verschiedener Lernorte in der beruflichen Bildung, 1st ed. Stuttgart: Klett, 1974, p. 69

[9] F. J. Kaiser and G. Pätzold, Wörterbuch Berufs- und Wirtschaftspädagogik, Bad Heilbrunn: Klinkhardt, 2006, pp. 354-355.

[10] D. Euler, "Lernortkooperation - eine unendliche Geschichte?" Handbuch der Lernortkooperation (Bd. 1: Theoretische Fundierung), Bielefeld: Bertelsmann (Forum Wirtschaftspädagogik), 2004, pp. 13, 14, 19-20.

[11] B. Justiz, Berufsbildungsgesetz, BbiG, Berlin: Bundesgesetzblatt, 2005

[12] K. Schubert and M. Klein, Das Politiklexikon, Bonn: Dietz, 2001.

[13] X. Rui, "The traditional apprenticeship comparative study of modern apprenticeship," Theory of Consumer Guide (Phase IV), 2008, p. 216

[14] J. Bi and L. Wang "Theoretical reflection over development of modern apprenticeship in China," China Training, vol. 8, pp. 14-16, 2012.

[15] Z. Zhao and J. Chen, "Apprenticeships in China's vocational education. History, Current Situation and Prospects," Chinese Vocational and Technical Education, vol. 18, 2013, p. 9.

[16] J. Henze, Berufliche Bildung des Auslands - Volksrepublik China, Baden-Baden: Nomos-Verl.-Ges, 1989, p. 53.

[17] Z. Zhao, "School-enterprise cooperation in China's vocational education and training," Assuring the Acquisition of Expertise. Apprenticeship in the Modern Economy, Beijing: Foreign Language Teaching and Research Press, 2011, pp. 43-52.

[18] H. Zimmermann, "Berufsbildung in China. Besonderheiten und aktuelle Entwicklung,"Das Bildungswesen in China. Reform und Transformation, Köln: Böhlau, 2003, pp. 204, 198-212.

[19] BiBB-Bundesinstitut für Berufsbildung. (July 2018). Verzeichnis der anerkannten Ausbildungsberufe 2018. Bonn: Bundesinstitut für Berufsbildung. [Online]. Available: https://www.bibb.de/dokumente/pdf/verzeichnis_anerkannter_ausbild ungsberufe_2018.pdf

[20] W. Georg, Strukturen und Strukturprobleme des Berufsbildungssystems, Fern Universität in Hagen, 2015, pp. 4-5, 6, 7-8.

[21] KMK-Kultusministerkonferenz, Handreichung für die Erarbeitung von Rahmenlehrplänen der Kultusministerkonferenz für den berufsbezogenen Unterricht in der Berufsschule und ihre Abstimmung mit Ausbildungsordnungen des Bundes für anerkannte Ausbildungsberufe, Berlin: Sekretariat der Kultusministerkonferenz, 2011, pp. 10-11.

[22] D. Euler and E. Severing, Flexible Ausbildungswege in der Berufsbildung, Nürnberg: St. Gallen, 2006, p. 20.

[23] S. Asmuth, E. Borsdorf, and G. Kirst, Verbundausbildung. Die Ausbildungsform der Zukunft. Programmstelle für das Programm Jobstarter, Bonn: BiBB Programmstelle, 2011, pp. 20-21.

[24] H. Schanz, Institutionen der Berufsbildung. Vielfalt in Gestaltungsformen und Entwicklung, Baltmannsweiler: Schneider Verlag Hohengehren, 2010, pp. 59-60.

Copyright $(2) 2019$ by the authors. This is an open access article distributed under the Creative Commons Attribution License which permits unrestricted use, distribution, and reproduction in any medium, provided the original work is properly cited (CC BY 4.0).

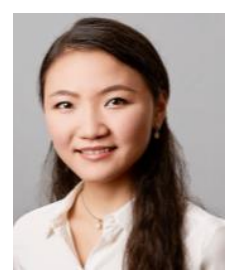

Xing Liu holds a B.A. in German philology from Tianjin Foreign Studies University (China, 2012) and a M.Sc. in international vocational education (profil technical and vocational education and training) from the Otto von Guericke University Magdeburg (Germany, 2014).

Since 2014 she is a $\mathrm{PhD}$ candidate and research fellow at the Institute for Vocational and Business Education / Didactics of Economics, Leuphana University of Lueneburg, Germany. Previously she has worked as an INTERPRETER and LECTURER among others for the Chamber of Industry and Commerce. Research interests: Vocational training for sustainable development, Sustainable development of retail training, International comparisons of vocational education and training.

Ms. Liu received an outstanding paper award at the International Postgraduate Roundtable \& Research Forum cum Summer School (Education University of Hong Kong, China, 2018). 
Lutz Leonard Schuppener holds a M.Sc. in business administration from the Linnaeus University (Kalmar, Sweden, 2010) and a M.A. in management \& entrepreneurship from the Leuphana University of Lueneburg, (Germany, 2012).

$\mathrm{He}$ is a business consultant in Berlin, Germany and a $\mathrm{PhD}$ candidate at the Institute for Management and Organisation, Leuphana University of Lueneburg, Germany. Previously he has worked as a scientific assistant at the German National Educational Panel Study (Leibniz Institute for Educational Trajectories) and the Center for Didactics at the University (University of
Augsburg, Germany). Research interests: Innovation management studies and innovation processes in small and medium-sized enterprises, change management and organizational learning.

Mr. Schuppener has received a Memorandum of Excellence from the Linnaeus University (Kalmar, Sweden) for his master's thesis on 'The Art of Leadership' and is an alumni of the Fast Track Doctoral Program at Leuphana University (Lueneburg, Germany). 